\title{
Clinical Presentation and Management of Coronavirus Disease 2019 in Renal Allograft Recipients: A Case Series
}

\author{
Abhijith C'1, Archin Ann Jacob'1, Sukanya Yesodhar', Sulfath TS', ,* \\ 'Department of Pharmacy Practice, S.C.S College of Pharmacy, Harapanahalli, Karnataka, INDIA. \\ ${ }^{2}$ Clinical Pharmacist, IQRAA International Hospital and Research Centre, Calicut, Kerala, INDIA.
}

\begin{abstract}
Complications of coronavirus disease 2019 infection in renal transplant recipients are associated with significant morbidity and mortality and the existence of co-morbidities are more likely to develop serious illness. In this case series the clinical outcomes of coronavirus disease 2019 in 6 recipients tested positive is explained. D-dimer, ferritin and C-reactive protein values are elevated in all cases. The patients were on immunosuppressant therapy and had stable graft function before coronavirus disease 2019 infection. After the diagnosis, management included reduction and withdrawal of immunosuppression and significant changes in corticosteroids. One of our patients showed significant improvement without dosage
\end{abstract}

adjustment of immunosuppressant.

Key words: Severe acute respiratory syndrome coronavirus 2, Rapid antigen test, Mycophenolate mofetil, Tacrolimus, Intravenous immunoglobulin.

Correspondence

Mrs. Sulfath TS,

Clinical Pharmacist, IQRAA International Hospital and Research Centre, Calicut-673009, Kerala, INDIA.

Email id: abhijithanu664@gmail.com

DOI: 10.5530/jyp.2021.13.62

\section{INTRODUCTION}

The coronaviruses has rapidly spread through the population of the world following the notification of the first COVID-19 case in December 2019 in Wuhan city, China. The causative organism of COVID-19 is severe acute respiratory system coronavirus 2 belongs to unique clade of the sarbecovirus subgenus within orthocoronavirinae subfamily. ${ }^{1}$ By February 25 2021, there were 444,996 new cases of COVID-19 worldwide and total number of deaths has reached over 2.5 million. ${ }^{2}$ India reported it's first confirmed case on 30 January 2020 from the state of Kerala, which was directly linked to Wuhan. Country wide lockdown and social distancing measures greatly contributed limiting the rapid spread of the disease. ${ }^{3}$ Gene sequencing of SARS-COV-2 unleashed the way of medical treatment of infected people. As a result, reverse transcription polymerase chain reaction has employed to diagnose the viral disease and chest computed tomography scan was shown to be more specific. ${ }^{4}$

Fatality rates help us analyzing the severity of a disease, identifying the populations at risk and evaluating the quality of health care. ${ }^{5}$ COVID-19 pneumonia is a serious illness, this may lead to complications and death in patients with other pre-existing comorbid conditions such as chronic obstructive pulmonary disease or asthma, chronic bronchitis, ischemic heart disease, hypertension and diabetes mellitus. ${ }^{6}$

Post-transplant patients are usually under immunosuppression which may result developing opportunistic infections. Sometimes organ transplantation is an individual risk factor for COVID-19 infection. ${ }^{7}$ Patients with RT also have high risk because of long term immunosuppression and other comorbidities. ${ }^{8}$ Till date, we don't have high level evidence of immunosuppression minimization strategies in infected transplant recipients. But still, the management of COVID-19 includes withdrawal and reduction of immunosuppressant. ${ }^{9}$ Patients with co-morbidities often need more attention since their condition is likely to worsen.

\section{CASE REPORT}

\section{Case 1}

A 49-year-old male who is a RT recipient since 2020, came with dyspnea and fever is a known case of insulin-dependent T2DM. The patient was on immunosuppression with tacrolimus, mycophenolate mofetil and prednisolone and RT-PCR tested positive. In view of COVID-19 infection mycophenolate mofetil dose was reduced and prednisolone dose $(10 \mathrm{mg})$ was increased to $15 \mathrm{mg}$, other medications include cotrimoxazole, aspirin-atorvastatin, silodosin, rabeprazole-domperidone, metoprolol, cilnidipine and insulin. On day 10, the rapid antigen test detection turned negative and the patient did not experience any other complaints. Hence mycophenolate mofetil dose was increased, tacrolimus dose was adjusted based on tac level and prednisolone dose was tapered to $10 \mathrm{mg} \mathrm{OD}$. The patient was symptomatically improved and discharged on day 12 .

\section{Case 2}

A 50-year-old male who had live donor RT on 2017 with history of T2DM and HTN, presented to hospital with headache and fever. His treatment included tacrolimus, mycophenolate mofetil and prednisolone. He was diagnosed with COVID-19 infection on October 27. Mycophenolate mofetil was stopped and the rest continued. Further management included azithromycin $500 \mathrm{mg}$ OD, calcium-vitamin D3 $500 \mathrm{mg}$ BD, zinc acetate $50 \mathrm{mg}$ OD and heparin $5000 \mathrm{IU}$. His chest X-ray detected bilateral pulmonary infiltration. Oxygen saturation improved to $95 \%$ with 4 litres oxygen from $86 \%$. On day 11 , he tested negative for SARSCOV-2 and transferred to ward on day 12 .

\section{Case 3}

A 56 years old male RT recipient (2010) with the history of T2DM and diabetic ketoacidosis since 20 years was shifted to our hospital on day 10

This is an open access article distributed under the terms of the Creative Commons Attribution-NonCommercial-ShareAlike 4.0 License, which allows others to remix, tweak, and build upon the work non-commercially, as long as the author is credited and the new creations are licensed under the identical terms. 
with complaints of cough, fever, and dyspnea. The RT-PCR from throat swab was positive for COVID-19 on October 16, 2020. He was on tacrolimus, mycophenolate mofetil and prednisolone. In view of COVID-19 infection, mycophenolate mofetil and tacrolimus were stopped. Oral prednisolone was changed to injection hydrocortisone. $\mathrm{He}$ was started on immunosuppression with cyclosporin $50 \mathrm{mg}$ BD. aspirin $150 \mathrm{mg} \mathrm{OD}$, nifedipine $10 \mathrm{mg} \mathrm{BD}$, atorvastatin $20 \mathrm{mg} \mathrm{OD}$, insulin glargine 10 units OD and heparin 2500 IU BD were continued. Considering opportunistic infections, meropenem, cotrimoxazole and voriconazole were started. The patient developed oliguria and acute graft dysfunction with serum creatinine $2.9 \mathrm{mg} / \mathrm{dl}$ and was initiated on renal replacement therapy (sustained low-efficiency dialysis). He developed one episode of generalized tonic-clonic seizure on day 12 and was started with fosphenytoin $150 \mathrm{mg}$ Q8H and levetiracetam $500 \mathrm{mg} \mathrm{BD}$. In view of hypoxia, patient was intubated and ventilated. On day 13 , the patient became negative for RAT. He was extubated and shifted out to ward on day 15. Mycophenolate mofetil $500 \mathrm{mg}$ was restarted and cyclosporine dose was adjusted based on trough levels $(42 \mathrm{mcg} / \mathrm{l})$. IV steroids were converted to oral prednisolone $60 \mathrm{mg}$ OD which was then tapered to $30 \mathrm{mg}$ OD.

\section{Case 4}

A 32-year-old male patient, who received a kidney graft on November 2019, presented with complaints of cough, headache and loose stools since 2 days. His immunosuppressive regimen included mycophenolate mofetil $360 \mathrm{mg} \mathrm{BD}$, prednisolone $7.5 \mathrm{mg} \mathrm{OD}$, tacrolimus $1.5 \mathrm{mg} \mathrm{BD}$ (trough level was $8.3 \mathrm{ng} / \mathrm{ml}$ ). He was also on beta-blockers. He was tested positive for COVID-19 nasal and throat swab, therefore he was hospitalized. The chest X-ray was clear, and kidney function tests were normal. The management included azithromycin $500 \mathrm{mg} \mathrm{OD}$, zinc acetate $50 \mathrm{mg}$ OD, racecadotril $100 \mathrm{mg}$ OD and calcium-vitamin D3 $500 \mathrm{mg}$. There was no adjustment made on immunosuppressive medication. On day 10, the patient became RAT negative and he was discharged from the hospital.

\section{Case 5}

A 38-year-old male patient, who received a kidney graft on November 2019 was admitted to the hospital with fever, myalgia and was tested positive for COVID-19 on October 2020. His immunosuppressive drugs consisted of tacrolimus, prednisolone and mycophenolate mofetil. In view of COVID-19 prednisolone dose $7.5 \mathrm{mg}$ was reduced and received treatment with azithromycin $500 \mathrm{mg} \mathrm{OD}$, dexamethasone $4 \mathrm{mg} \mathrm{BD}$, zinc acetate $50 \mathrm{mg}$ OD, cotrimoxazole $800 / 160 \mathrm{mg}$ OD and calcium-vitamin D3 $500 \mathrm{mg}$ OD. Blood culture revealed methicillin resistant staphylococcus aureus growth for which vancomycin was initiated. Thereafter patient's condition was getting worse, mycophenolate mofetil was stopped and tacrolimus $0.75 \mathrm{mg} \mathrm{BD}$ was reduced to $0.5 \mathrm{mg}$ (trough level was $9.8 \mathrm{ng} / \mathrm{mL}$ ). On the 16th day in hospital, patient condition had significantly improved and the analysis of throat swab was negative. Two days later, patient was discharged from the hospital.

\section{Case 6}

A 41-year-old male patient with history of T2DM and HTN with a kidney graft on September 2017 presented to the hospital with complaints of fever, cough and dyspnea. His immunosuppressive agents were prednisolone, mycophenolate mofetil and tacrolimus. The patient was diagnosed with COVID-19 infection. Mycophenolate mofetil was stopped and prednisolone dose was reduced to $7.5 \mathrm{mg}$ OD from $10 \mathrm{mg}$. On initial assessment, his oxygen saturation was $92 \%$ and blood pressure was $170 / 90 \mathrm{mmHg}$. Instantly started positive airway pressure and his oxygen saturation improved to $97 \%$. The patient was empirically treated for leucocytosis with azithromycin and the chest X-ray showed bilateral pulmonary infiltrates. Other medications included insulin glargine 10 units $\mathrm{OD}$, amlodipine $5 \mathrm{mg}$ OD, cotrimoxazole 800/160 mg OD, aspirin $75 \mathrm{mg} \mathrm{OD}$, metoprolol $12.5 \mathrm{mg} \mathrm{BD}$, teneligliptin $20 \mathrm{mg} \mathrm{OD}$, dexamethasone $6 \mathrm{mg}$ OD, salbutamol $10 \mathrm{mg}$ TID, pantoprazole $40 \mathrm{mg}$ OD and intravenous immunoglobulin. Following 20 days course in hospital, patient became asymptomatic and was screened negative in RAT. The dose of prednisolone was increased to $20 \mathrm{mg}$ OD and mycophenolate mofetil was restarted. The patient had a good clinical outcome and was discharged.

\section{DISCUSSION}

The management of COVID-19 among the RT recipients still have many uncertainties. Mortality rate is considerably low in general population, although fatal cases have been reported in patients with advanced age and other co-morbidities. In this case series we discussed about 6 cases of COVID-19 in post-transplant recipients. Renal allograft recipients are immunocompromised, thus the chance of getting severe infections are high, particularly in the patients who are having DM and HTN. ${ }^{10-12}$ In our hospital 4 out of 6 were having DM, HTN and remaining were without any co-morbidities.

As per World Health Organisation, in COVID-19 people will develop different symptoms, among them the most common were fever ,dry cough and tiredness, serious were dyspnea, loss of speech and chest pain. ${ }^{13}$ In our scenario the patients had multiple symptoms, in which fever was common followed by cough, dyspnea, headache, myalgia and diarrhoea.

According to the IFCC guidelines, in COVID-19 the D-dimer, C-reactive protien and serum ferritin levels would be higher than normal range, the same trend was seen in our patients also (Table 1). ${ }^{14}$ The first case of posttransplant COVID-19 was reported in a 52 years old Chinese recipient. With the discontinuation of immunosuppressive therapy and treating with low dose of methyl prednisolone, nebulized interferon alpha and polyclonal IVIG gave a great response. ${ }^{15}$

During the beginning stages of pandemic, without knowing the scenario different treatment protocols were invaded. In majority of patients immunosuppressant were reduced considering mycophenolate mofetil has been reported to increase the risk of opportunistic infections, including viral infection. ${ }^{11,16}$ In view of COVID-19 mycophenolate mofetil was stopped in 3 of 6 patients. Few patients showed supratherapeutic tarcolimus levels which was due to pharmacological interaction resulting in nephrotoxicity, further resulted in reducing the dose. ${ }^{17}$

The recent recovery trials exposed that the use of corticosteroids in COVID-19 as an anti-inflammatory agent had shown better outcomes in patients. The use of low dose corticosteroids helped in improving oxygenation, lung tissue damage and reduce mortality rate. ${ }^{18-20}$ In some of our patients the dose of prednisolone was increased for additional

Table 1: Laboratory parameters of patients at presentation.

\begin{tabular}{ccccc}
\hline Case & $\begin{array}{c}\text { Serum } \\
\text { creatinine } \\
(\mathrm{mg} / \mathrm{dL})\end{array}$ & $\begin{array}{c}\text { Ferritin } \\
(\mathrm{ng} / \mathrm{mL})\end{array}$ & $\begin{array}{c}\text { D-dimer } \\
(\mathrm{ng} / \mathrm{mL})\end{array}$ & $\begin{array}{c}\text { CRP } \\
(\mathrm{Mg} / \mathrm{L})\end{array}$ \\
\hline 1 & 1.5 & 980.4 & 2155.8 & 31.2 \\
2 & 2.8 & 180.9 & 1054.9 & 29.7 \\
3 & 1.2 & 276.9 & 792 & 57.9 \\
4 & 1.8 & 370.5 & 867.5 & 52.8 \\
5 & 6.08 & 631.4 & 920.93 & 69.6 \\
6 & 5.6 & 1116 & 1967.1 & 21.8 \\
\hline
\end{tabular}


effects and there was improvement without changing the dose of other immunosuppressants.

\section{CONCLUSION}

Our findings suggests that modification of immunosuppression in posttransplant patients with COVID-19 has significant favorable effects in disease morbidity and mortality. Corticosteroids, IVIG and other supportive treatments helped providing positive clinical outcomes and reducing mortality rates. The increased morbidity and mortality from SARS-COV-2 does not depend on transplant recipient status but depends on existing co-morbidities while comparing with general population.

\section{CONFLICT OF INTEREST}

The authors declare no conflict of interest.

\section{ABBREVIATION}

COVID-19: Coronavirus disease 2019; SARS-COV-2: Severe acute respiratory system coronavirus 2; RT-PCR: Reverse transcription polymerase chain reaction; HTN: Hypertension; T2DM: Type 2 diabetes mellitus; RT: Renal transplant; RAT: Rapid antigen test; IVIG: Intravenous immunoglobulin.

\section{REFERENCE}

1. Lu R, Zhao X, Li J, Niu P, Yang B, Wu H, et al. Genomic characterisation and epidemiology of 2019 novel coronavirus: implications for virus origins and receptor binding. Lancet. 2020;395(10224):565-74. doi: 10.1016/S0140-6736(20)30251-8, PMID 32007145.

2. World Health Organization, WHO. Coronavirus (COVID-19) dashboard. 2021 [cited Feb 25 2021]. Available from: https://covid19.who.int/.

3. Jahan N, Rubeshkumar P, Karuppiah M, Sambath I, Sendhilkumar M, Ilangovan K, Ongesh R, Sakthivel M, Mohankumar R, Santhosh Kumar M, Ganeshkumar P, Ponnaiah M, Kaur P. Entry and initial spread of COVID-19 in India: epidemiological analysis of media surveillance data, India, 2020. Clin Epidemiol Glob Health. 2021;9:347-54. doi: 10.1016/j.cegh.2020.10.008, PMID 33195880.

4. World Health Organization. Laboratory testing for coronavirus disease 2019 (COVID-19) in suspected human cases: interim guidance; 2020. Available from: https://apps.who.int/iris/handle/10665/331329 [cited 29/6/2021].

5. World Health Organization. Estimating mortality from COVID-19: scientific brief; 2020. Available from: https://apps.who.int/iris/handle/10665/333642 [cited 29/6/2021].

6. Ejaz $H$, Alsrhani A, Zafar A, Javed $H$, Junaid $K$, Abdalla AE, Abosalif KOA, Ahmed Z, Younas S. COVID-19 and comorbidities: deleterious impact on infected patients. J Infect Public Health. 2020;13(12):1833-9. doi: 10.1016/j. jiph.2020.07.014, PMID 32788073.

7. AzziY, Parides M, Alani O, Loarte-Campos P, Bartash R, Forest S, et al. COVID-19 infection in kidney transplant recipients at the epicenter of pandemics. Kidney Int. 2020;98(6):1559-67. doi: 10.1016/j.kint.2020.10.004, PMID 33069762.

8. Elhadedy MA, Marie Y, Halawa A. COVID-19 in renal transplant recipients: case series and a brief review of current evidence. Nephron. 2021;145(2):192-8. doi: 10.1159/000512329, PMID 33291120.

9. Daoud A, Alqassieh A, Alkhader D, Posadas Salas MA, Rao V, Fülöp T, et al. Immunosuppression in kidney transplant recipients with COVID-19 infection where do we stand and where are we heading? Ren Fail. 2021;43(1):273-80. doi: 10.1080/0886022X.2021.1876730, PMID 33491531.

10. Zhou F, Yu T, Du R, Fan G, Liu Y, Liu Z, Xiang J, et al. Clinical course and risk factors for mortality of adult inpatients with COVID-19 in Wuhan, China: a retrospective cohort study. Lancet. 2020;395(10229):1054-62. doi: 10.1016/ S0140-6736(20)30566-3, PMID 32171076.

11. Bhatraju PK, Ghassemieh BJ, Nichols M, Kim R, Jerome KR, Nalla AK, et al. Covid-19 in critically ill patients in the Seattle region - case series. N Engl J Med. 2020;382(21):2012-22. doi: 10.1056/NEJMoa2004500, PMID 32227758.

12. Nair V, Jandovitz N, Hirsch JS, Nair G, Abate M, Bhaskaran M, et al. COVID-19 in kidney transplant recipients. Am J Transplant. 2020;20(7):1819-25. doi: 10.1111/ ajt.15967, PMID 32351040.

13. World Health Organization. Coronavirus-WHO. 2021 [cited Feb 7 2021]. Available from: https://www.who.int/health-topics/coronavirus\#tab=tab-3.

14. ins oft Denmark h. IFCC Interim Guidelines on COVID-19 Testing in Clinical Laboratories-October 2020-; 2021. IFCC. Ifcc.org [cited Feb 10 2021]. Available from: https://www.ifcc.org/ifcc-communications-publications-division$\mathrm{cpd} /$ newsarchive-links/ifcc-interim-guidelines-on-covid-19-testing-in-clinicallaboratories-october-2020/.

15. Zhu L, Xu X, Ma KE, Yang J, Guan H, Chen S, Chen Z, Chen G. Successful recovery of COVID-19 pneumonia in a renal transplant recipient with long-term immunosuppression. Am J Transplant. 2020;20(7):1859-63. doi: 10.1111/ajt.15869, PMID 32181990.

16. Adapa S, Konala VM, Naramala S, Daggubati SR, Koduri NM, Gayam V, Chenna A COVID-19 in renal transplant patient presenting with active typical symptoms and resolved atypical symptoms. J Investig Med High Impact Case Rep. 2020;8:2324709620949307. doi: 10.1177/2324709620949307, PMID 32779481.

17. Devresse A, Belkhir L, Vo B, Ghaye B, Scohy A, Kabamba B, et al. COVID-19 infection in kidney transplant recipients: a single-center case series of 22 cases from Belgium. Kidney Med. 2020;2(4):459-66. doi: 10.1016/j.xkme.2020.06.001, PMID 32775986.

18. Johnson KM, Belfer JJ, Peterson GR, Boelkins MR, Dumkow LE. Managing COVID-19 in renal transplant recipients: a review of recent literature and case supporting corticosteroid-sparing immunosuppression. Pharmacotherapy. 2020;40(6):517-24. doi: 10.1002/phar.2410, PMID 32339304.

19. Alberici F, Delbarba E, Manenti C, Econimo L, Valerio F, Pola A, et al, Brescia Renal COVID Task Force. Management of patients on dialysis and with kidney transplantation during the SARS-CoV-2 (COVID-19) pandemic in Brescia, Italy. Kidney Int Rep. 2020;5(5):580-5. doi: 10.1016/j.ekir.2020.04.001, PMID 32292866.

20. Ko JJ, Wu C, Mehta N, Wald-Dickler N, Yang W, Qiao R. A comparison of methylprednisolone and dexamethasone in intensive care patients with COVID-19. J Intensive Care Med. 2021;36(6):673-80. doi: 10.1177/0885066621994057, PMID 33632000. 